\title{
Temperature Dependence of Grating-Assisted Coupling to Small Silicon Waveguides
}

\author{
G. Z. Mashanovich, B. Patel, V. Nsengumuremyi, D. Thomson, S. Howe, \\ W. R. Headley, V. M. N. Passaro, G. J. Ensell, and G. T. Reed
}

\begin{abstract}
Coupling optical fibres with small silicon waveguides can present a challenge due to a large difference in refractive index and dimensions between the two. Here we investigate the temperature influence on a grating-assisted directional coupler.
\end{abstract}

\section{INTRODUCTION}

The reduction of a waveguide's cross sectional dimensions can enhance the performance of the photonic devices [1-3]. However, it makes coupling of light to/from the circuit very difficult, particularly to/from standard optical fibres that typically have a core dimension of $\sim 9$ $\mu \mathrm{m}$. Several devices have been proposed for efficient coupling to/from the silicon photonic circuit, the most popular approaches being taper and grating couplers [e.g. 4-6]. We have previously presented theoretical work on an alternative device entitled the Dual Grating Assisted Directional Coupler (DGADC) [7] and experimental results of devices that were fabricated in Silicon on Insulator (SOI) technology [8].

Figure 1 shows a schematic of the coupler. The light from a fibre is coupled to the thick silicon oxynitride waveguide (with refractive index close to that of the fibre), and via the first grating to the intermediate silicon nitride layer, and after that to the thin silicon waveguide using the second grating. The thick input waveguide and the two separation layers are fabricated in silicon oxynitride technology because of the ability to control the refractive index over a broad range. The silicon nitride waveguide is crucial for the operation of the coupler because it bridges the gap between the fibre and silicon refractive indices.

Plasma Enhanced Chemical Vapour Deposition (PECVD) was used for the fabrication of $\mathrm{SiON}$ and $\mathrm{Si}_{3} \mathrm{~N}_{4}$ layers on SOI wafers [8]. Gratings with period of $1.3-1.4$ $\mu \mathrm{m}$ and $10 \mathrm{~nm}$ in height, and with period of $\approx 5 \mu \mathrm{m}$ and height of $20 \mathrm{~nm}$ were patterned by plasma etching on the tops of the $\mathrm{Si}$ and $\mathrm{Si}_{3} \mathrm{~N}_{4}$ waveguides, respectively.

G. Z. Mashanovich, V. Nsengumuremyi, B. Patel, D. Thomson, S. Howe, W. R. Headley, and G. T. Reed are with the Advance Technology Institute, University of Surrey, Guildford, Surrey, GU2 7XH, UK, E-mail: g.mashanovich@surrey.ac.uk

V. M. N. Passaro is with the Dipartimento di Elettrotecnica ed Elettronica, Politecnico di Bari, Via Orabona 4, 70125, Bari, Italy

G. J. Ensell is with the School of Electronics and Computer Sciences, University of Southampton, SO17 1BJ, UK.

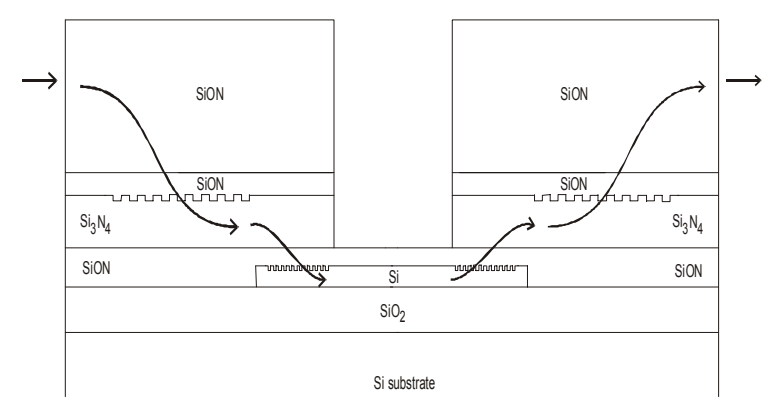

Fig. 1. Dual grating-assisted directional coupler in SOI technology [8].

Theoretical investigation of the coupler has shown that a coupling efficiency in excess of $90 \%$ can be obtained [7], while a measured efficiency for coupling to $230 \mathrm{~nm}$ thick silicon waveguide was 55\% [8], which was the best result for grating-based coupling to such small semiconductor waveguides reported in the literature at the time. In this paper we present an investigation of the influence of temperature on the coupler performance as well as demonstrate an improvement in the coupling efficiency due to changes in the temperature.

\section{EXPERIMENTAL RESULTS}

Unlike our previous devices [8], the couplers investigated in this paper have a top $\mathrm{SiON}$ layer thickness of $\approx 4.4 \mu \mathrm{m}$, corresponding to a maximum theoretical coupling efficiency of $\sim 70 \%$ when the other layers have their optimum thicknesses. Further improvement of the coupling efficiency can be expected for an optimum SiON thickness of $5 \mu \mathrm{m}$.

Each sample contains a number of devices with different grating periods, enabling a shift of the resonant peak towards longer or shorter wavelengths while still achieving high coupling efficiency. The maximum coupling efficiency at room temperature in the C-band wavelength range was $56 \%$, whilst in the L-band, efficiency of $43 \%$ was measured [9] representing an increase of $11 \%$ compared to the results reported in [8].

The temperature dependence of the resonant peak has been measured on a number of devices. One example is shown in Fig. 2. The temperature of the samples was varied from $5^{\circ} \mathrm{C}$ to $90^{\circ} \mathrm{C}$. As the refractive index changes with 
temperature, a wavelength shift of the resonant peak can be expected due to the thermo-optic effect. Consequently, coupling efficiency will also change. The average peak shift was found to be $0.15 \pm 0.01 \mathrm{~nm} /{ }^{\circ} \mathrm{C}$. This result was compared with theoretical predictions obtained by the Transfer Matrix Method (TMM) [10] and Floquet-Bloch Method (FBT) [11], using the following thermo-optic coefficients: $\beta_{\mathrm{SiO} 2}=\beta_{\mathrm{SiON}}=\beta_{\mathrm{Si} 3 \mathrm{~N} 4}=10^{-5} \mathrm{~K}^{-1}[12], \beta_{S i}=1.86$ $\times 10^{-4} \mathrm{~K}^{-1}$ [13]. Theoretical peak shift obtained by the $\mathrm{TMM}$ and FBT is $0.177 \mathrm{~nm} /{ }^{\circ} \mathrm{C}$, and $0.170 \mathrm{~nm} /{ }^{\circ} \mathrm{C}$, respectively. The difference between the experimental and theoretical values can be due to the temperature distribution in the sample. It is plausible that the thermal conductivity of the various layers can cause the device to have temperatures different to that of the Peltier element used in the experiment. The difference in the temperature of 5$10^{\circ} \mathrm{C}$ can explain the difference between the experimental and theoretical values.

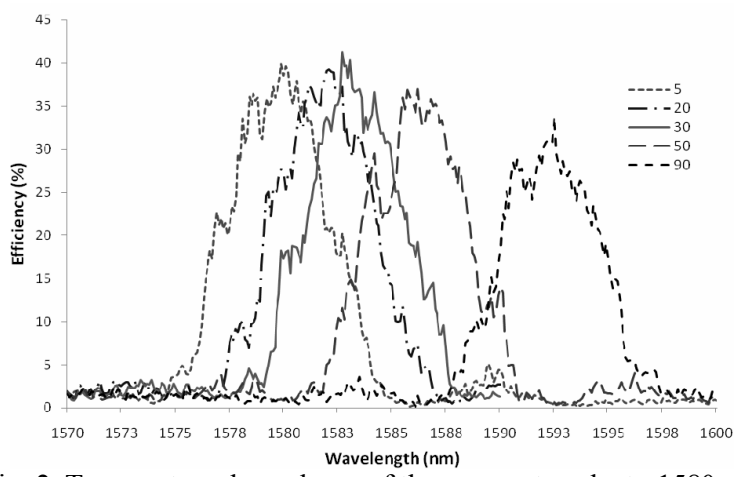

Fig. 2. Temperature dependence of the resonant peak at $\sim 1580 \mathrm{~nm}$

For $\Delta T=15-20^{\circ} \mathrm{C}$, the output at the resonant wavelength for $T=20^{\circ} \mathrm{C}$, drops by $\sim 3 \mathrm{~dB}$. In other words, temperature variations of $\pm 15-20^{\circ} \mathrm{C}$ results in output reduction of $\leq 3 \mathrm{~dB}$ at fixed wavelengths. To increase this temperature tolerance, the FWHM of the resonant peak has to be broadened. The spectrum of the devices can be broadened by varying the duty cycle of the gratings. It is expected that the FWHM can be increased from the current value of $5 \mathrm{~nm}$ to $\sim 12-13 \mathrm{~nm}$ thus significantly improving the temperature tolerance of the device. Further broadening could be obtained by grating chirping.

In some cases, the coupling coefficient can be improved by changing the temperature of the device. One such example is shown in Fig. 3, where better matching of the grating resonant peaks in the DGADC (Fig. 1) are achieved at $25^{\circ} \mathrm{C}$ rather than at the room temperature. It can be seen from Figure 3, that the left side lobe is decreasing, whilst the right side lobes are increasing in amplitude as the temperature increases. This is a consequence of different thermo-optic coefficients between the layers. Therefore, for an optimum temperature, the coupling coefficient is maximized. The maximum efficiency of $59 \%$ has been measured at the temperature of $25^{\circ} \mathrm{C}$, representing the highest value measured for a grating-assisted directional coupling to date. The propagation loss in the DGADC has not been taken into account in the efficiency calculation, as explained in [8].

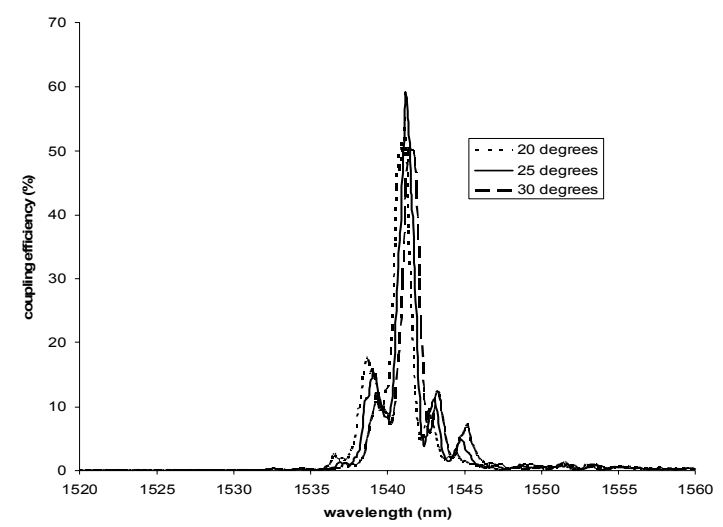

Fig. 3. Maximum coupling efficiency of $59 \%$ measured at temperature of $25^{\circ} \mathrm{C}$

As silicon oxynitride and nitride layers have been deposited by the PECVD method, propagation loss can be relatively high in these layers [14]. Therefore, annealing at high temperatures is sometimes needed to reduce the propagation loss [15]. We performed annealing at temperatures in the $600-1100^{\circ} \mathrm{C}$ range [16]. The propagation loss has been significantly reduced by annealing. For example, at the wavelength of $1550 \mathrm{~nm}$ the loss was $16 \mathrm{~dB} / \mathrm{cm}$ before annealing, and was reduced to $1.1 \mathrm{~dB} / \mathrm{cm}$ after annealing at $900^{\circ} \mathrm{C}$ for 1 hour. Further reductions can be expected for longer annealing times.

\section{CONCLUSION}

The temperature dependence of the resonant peak of the Dual Grating-Assisted Directional Coupler has been investigated. It has been shown that temperature variations of $\pm 15-20{ }^{\circ} \mathrm{C}$ result in a $3 \mathrm{~dB}$ reduction of the output signal at a fixed wavelength. This temperature dependence can be broadened by grating chirping and by varying the duty cycle of the gratings. Theoretical predictions, obtained by the TMM and FBT, and experimental results of the peak wavelength shift by changing the temperature in the $5-90^{\circ} \mathrm{C}$ range are in a good agreement. Maximum coupling efficiency of $59 \%$ has been measured at the temperature of $25^{\circ} \mathrm{C}$, which is the highest measured value for a gratingassisted directional coupling to small silicon waveguides. Annealing has been also performed which has significantly reduced the propagation loss in the PECVD deposited layers.

\section{ACKNOWLEDGEMENT}

The authors would like to thank Tony Blackburn and Mike Josey of Innos Ltd for their contribution in the fabrication of the devices, and Nick Bennett and Justin 
Hamilton from the University of Surrey for annealing of the samples. The authors are grateful to University of Surrey and EPSRC, UK for funding. This work has been also partially supported by Interlink project no. II04C01CDM.

\section{REFERENCES}

[1] A. Liu, L. Liao, D. Rubin, H. Nguyen, B. Ciftcioglu, Y. Chetrit, N. Izhaky, and M. Paniccia, "High-speed optical modulation based on carrier depletion in a silicon waveguide," Opt. Express, vol. 15, pp. 660-668, 2007.

[2] H. Rong, R. Jones, A. Liu, O. Cohen, D. Hak, A. Fang, and M. Paniccia, "A continuous-wave Raman silicon laser," Nature, vol. 433, pp. 725-728, 2005.

[3] V. R. Almeida, C. A. Barrios, R. R. Panepucci, and M. Lipson, "All-optical control of light on a silicon chip," Nature, vol. 431, pp. 1081-1084, 2004.

[4] A. Sure, T. Dillon, J. Murakowski, C. Lin, D. Pustai, and D. W. Prather, "Fabrication and characterization of threedimensional silicon tapers," Opt. Express, vol. 11, pp. 3555$3561,2003$.

[5] V. R. Almeida, R. R. Panepucci, and M. Lipson, "Nanotaper for compact mode conversion", Opt. Lett., vol. 28, pp. 1302-1304, 2003.

[6] Z. Lu and D. W. Prather, "TIR-Evanescent coupler for fiber to waveguide integration of planar optoelectronic devices," Opt. Lett., vol. 29, pp. 1784-1750, 2004.

[7] G. Z. Masanovic, V. M. N. Passaro, and G. T. Reed, "Dual grating-assisted directional coupling between fibres and thin semiconductor waveguides," IEEE Photon. Technol. Lett., vol. 15, pp. 1395-1397, 2003.
[8] G. Z. Masanovic, G. T. Reed, W. Headley, B. Timotijevic, V. M. N. Passaro, R. Atta, G. Ensell, and A. G. R. Evans, "A high efficiency input/output coupler for small silicon photonic devices," Opt. Express, vol. 13, pp. 7374-7379, 2005.

[9] G. Z. Mashanovich, V. M. N. Passaro, G. J. Ensell, F. Y. Gardes, and G. T. Reed, "Improved dual grating-assisted directional coupler for silicon nanophotonics," Proc. $25^{\text {th }}$ IEEE Conf. Microelectron. MIEL 2006, Belgrade, Serbia, 1417 May 2006, pp. 289-292.

[10] W. Huang and J. Hong, "Transfer matrix approach based on local normal modes for coupled waveguides with periodic perturbation," J. Lightwave Technol., vol. 10, pp. 1367-1375, 1992.

[11] V. M. N. Passaro, "Optimal Design of grating-assisted directional couplers," J. Lightwave Technol., vol. 18, pp. 973984,2000

[12] L. Eldada, "Advances in telecom and datacom optical components," Opt. Eng., vol. 40, pp. 1165-1178, 2001.

[13] G. T. Reed and A. P. Knights, Silicon Photonics: An Introduction, Chichester, UK: Wiley, 2004.

[14] K. Worhoff, A. Driessen, P. V. Lambeck, L. T. H. Hilderink, P. W. Linders, and Th. J. A. Popma, "Plasma enhanced chemical vapor deposition silicon oxynitride optimized for application in integrated optics," Sensors and Actuators A, vol. 75, pp. 9-12, 1999.

[15] K. E. Mattsson, "Plasma-enhanced growth, composition, and refractive index of silicon oxy-nitride films," J. Appl. Phys., vol. 77, pp. 6616-6623, 1995.

[16] G. Z. Mashanovich, V. Nsengumuremyi, B. Patel, D. Thomson, N. Bennett, W. R. Headley, V. M. N. Passaro, G. J. Ensell, and G. T. Reed, "Directional coupling to small silicon photonic waveguides," (submitted). 